\title{
Social implications of technology: Introductory words
}

\author{
Herbert F. Voigt ${ }^{1}$
}

Received: 1 December 2015 / Accepted: 3 December 2015 / Published online: 10 February 2016

(C) IUPESM and Springer-Verlag Berlin Heidelberg 2016

This special issue of Health and Technology is a tribute to the life and work of Lodewijk Bos. Dr. Bos was especially interested in this topic and served as Co-Editor-in-Chief of this Journal together with Luis Kun.

The importance of technology's impact on society has previously been considered (see for example Marcuse [1]). At the center of the social implications of technology are humans - it is humans who make the technology and humans who benefit, or are harmed, by it. That is not to say that other species do, or do not, benefit from, or are harmed by, human technologies, just that they are not contributors to what we term technology. Technology, per se, is amoral, apolitical and irreligious. It is neither capable of doing good nor doing evil. Only human use of technology for good or evil is possible. Human use of technology for good is laudable. The capacity, however, for humans to use technology for evil is frightening; and yet it appears daily on our information delivery systems.

Perhaps by looking at one technology that has been developed over time we can see the possible ramifications of the social impact of technology on human behavior. Let us take the simple remote control as an example. In 1950, the Zenith Radio Corporation introduced the "Lazy Bones" remote to control the television by wire. This was an attempt by humans to control a device without having to stand up, walk over to the set to change the channel and then walk back to the

This article is part of the Topical Collection on Social Implications of Technologies

Herbert F. Voigt

hfv@bu.edu

1 International Union for Physical and Engineering Sciences in Medicine, Boston University Biomedical Engineering, 44 Cummington Mall, Boston, MA 02115, USA comfort of a nice chair or sofa. I imagine the wire could be annoying and served as impetus for the invention of the wireless remote by Eugene Polley in 1955 [2]. The development of the modern remote involved many turns and twists of technologies - mechanical, electrical, ultrasound, light, infrared, and now Bluetooth. The desire of humans to control objects at a distance wirelessly is satisfied by this technology. To the average person, however, the mechanisms of this action-at-adistance is no more understood than the wand action by Harry Potter or his magical friends and enemies. In fact, understanding the myriad complexities of modern devices can be daunting even for many highly educated people, including those in the sciences and engineering. Interacting with modern technology can be a mystical and magical affair. It is cliché for parents to need to ask their children to program their remotes. Indeed, televisions are not the only objects we wish to control. Consider garage doors, gas fireplaces, fans, video games, computers, robots, drones, etc.; all need to be controlled remotely. We do not even need to be located physically near the controlled devices; now we can control our home appliances, lights and locks far from our home from the other side of the world with our smart phones. These are the toys of our modern society. It is not too difficult to go from the modern remote control to driverless automobiles and the goal of eliminating many of the estimated 1.24 million deaths worldwide in the year due to road accidents (data from 2010) [3].

All of us reading this are affected by technology every day, and yet about 2.4 billion people on Earth do not have access to toilets [4]. In which of C.P. Snow's two cultures do these folks belong [5]? Snow referred to the growing gap emerging between the culture of Science and the culture of the Humanities. Although both groups are considered highly educated, those in the humanities would scoff at scientists who did not know about Shakespeare and scientists would scorn humanists who did not understand the laws of thermodynamics. I do not think 
Snow would have the sanitation-facility-free group in either the scientific or humanities culture. So how do we refer to this group? They are certainly not members of the Third Culture [6], the emerging nerd culture of technology. Perhaps they are part of the Fourth World [7]. "The Fourth World is an extension of the Three Worlds Theory, used variably to refer to: Sub-populations socially excluded from global society; Hunter-gatherer, nomadic, pastoral, and some subsistence farming peoples living beyond the modern industrial norm [8]. Sub-populations existing in a First World country, but with the living standards of those of a Third World, or developing country." Although this group of people almost certainly has their intelligence distributed normally along a typical bell-shaped curve, they lack educational opportunities that would help them thrive in a modern society. The social importance of modern technology on this third of the human population is potentially profound. The boundaries of the "culture" of the uneducated, however, are not limited to those living in abject squalor; we find many of them living among Snow's two cultures throughout the world, including the modern world; maybe they make up the Fourth World. What are we to do?

Educating Fourth World people is a herculean task that needs to remain a prime objective. Doing so without modern technology, however, is impossible. "To achieve universal primary education" was the second of eight Millennium Development Goals adopted at the Millennium Summit of the United Nations in 2000 [9]. UNESCO and UNICEF concluded in Fixing the Broken Promise of Education for All that this goal was not achieved in 2015, as promised [10, 11]! While considerable attention is being focused on providing medical attention to this population (another Millennium Development Goal), equal attention should be given to educating them as well. Education is an essential tool in fighting the causes of diseases. Modern technology makes the impossible possible.

We can clearly bring our TV remotes, as well as TVs, to the Fourth World, and rest assured that they will learn to use them. What we also need to do is to bring our unbiased knowledge of the modern world, literacy and numeracy to the Fourth World, before it is too late!

Acknowledgements Ronit G. Voigt is thanked for commenting on previous versions of this article.

\section{Compliance with ethical standards}

Conflict of interest The author declares that he has no conflict of interest.

\section{References}

1. Marcuse, Herbert "Some Social Implications of Modern Technology" Studies in Philosophy and Social Sciences Vol. IX (1941).

2. https://en.wikipedia.org/wiki/Eugene_Polley

3. https://en.wikipedia.org/wiki/List_of_countries_by_traffic-related_ death rate

4. http://time.com/3942630/toilets-who-unicef-report/

5. Snow, Charles Percy (2001) [1959]. The Two Cultures. London: Cambridge University Press. p. 3. ISBN 0-521-45730-0

6. Kelly, Kevin The Third Culture, Science Magazine 13 February 1998279 (5353): 992-993.

7. https://en.wikipedia.org/wiki/Fourth_World

8. "International day of the world's indigenous people". Asian Center for the Progress of Peoples

9. https://en.wikipedia.org/wiki/Millennium_Development_Goals

10. http://www.data.unicef.org/corecode/uploads/document6/ uploaded_pdfs/corecode/UNESCO-OOSC-EXS-Eng-web_217. pdf

11. http://www.data.unicef.org/education/overview.html 